\title{
O Conceito de Letramento e a Teoria da Gramática: Uma Vinculação Necessária para o Diálogo entre as Ciências da Linguagem e a EducaÇão
}

(The Concept of Literacy and the Theory of Grammar: A Necessary

Bind to the Dialogue between Language Sciences and Education)

\author{
Luiz Antonio Gomes SenNA \\ (Programa de Pós-Graduação em Educação \\ Universidade do Estado do Rio de Janeiro)
}

\begin{abstract}
The concept of Literacy built in parallel with a broaden discussion about general guide-lines of the Theory of Grammar and it's phenomenology; explanatory adequacy and learnability condition in metaphoric frameworks controlled by buman communicative intentions; different text systems permeability explained in terms of knowledge models priority, enrolling a set of mental systems that command the structure of oral and written languages. This paper analyses some logical determinations towards an inter / multidisciplinary approach of Literacy and mental grammar.
\end{abstract}

KEY-WORDS: theory of grammar; literacy; metaphoric explanatory models.

RESUMO: O conceito de letramento construído em paralelo com uma discussão ampliada sobre a teoria da gramática e sua fenomenologia; adequação explanatória e condição de aprendizibilidade em sistemas metafóricos controlados pelas intençôes comunicativas bumanas; a permeabilidade entre diferentes sistemas textuais explicada em termos de prioridade dos modos do pensamento, envolvendo um conjunto de modelos mentais que comandam a estrutura da fala e da escrita. Este artigo analisa algumas determinações lógicas em favor de uma abordagem inter/multidisciplinar do letramento e gramáticas mentais.

PALAVRAS-CHAVE: teoria da gramática; letramento; modelos explanatórios metafóricos.

Discutir o conceito de letramento na contemporaneidade significa mais do que uma simples (bem... não tão simples) definição teórico-conceitual 
sobre sua natureza fenomenológica. Vimos incorrendo neste erro há longa data, desprezando na ponta do lápis toda a complexidade cultural que, para além das práticas acadêmicas, imprime um sentido social ao letramento e lhe determina uma série de condições de implementação, seja dentro, ou fora, do contexto escolar. Diferentemente de outras teorias possíveis, a que se reporta ao conceito de letramento ganha materialidade fora do contexto acadêmico, concebendo-se, portanto, como algo a ser absorvido pela cultura imanente às práticas sociais, não sujeita a determinações acadêmicas. Daí resulta que sua construção deve se dar com certa isenção, relativamente à precedência dos preceitos científicos já estabelecidos sobre os demais, não científicos, presentes na sociedade.

O conceito de letramento, por si mesmo, não é capaz de dar sustentação às práticas escolares, à medida que boa parte de seu objeto relaciona-se à estrutura da língua que se busca representar na escrita. Por este motivo, ainda que se possa tratar do letramento como um conceito isolado na Educação, é impossível concebê-lo à margem da teoria da gramática, da qual se esperam explicações acerca de fenômenos lingüísticos encontrados pelo professor no cotidiano escolar. Este artigo problematiza o potencial de teorias de gramática quanto à apresentação de soluções descritivas para os fatos verificados quando em textos que conjuguem propriedades da fala e da escrita simultaneamente, a exemplo do que se dá regularmente no processo de letramento. Apresentam-se, inicialmente, questões relativas à natureza dos sistemas arrolados como base das teorias gramaticais, bem como a sua vinculação a modelos mentais idealizados à margem do sujeito falante em condições normais de interação comunicativa. Em prosseguimento, considerando-se um conjunto de textos que tipificam situações produzidas ordinariamente no processo de letramento, descreve-se a questão concreta a ser absorvida pela teoria da gramática, a qual se caracteriza pela confluência de sistemas sob controle do sujeito falante, com base em suas intenções comunicativas e nos modos de estruturação do pensamento. A partir daí, na seção seguinte, defendem-se elementos para a configuração de um modelo teórico de descrição gramatical capaz de absorver no corpo de suas categorias operacionais fatores como a intencionalidade e os modos do pensamento, tornando-se, deste modo, capaz de explicar a estrutura de textos em que se verificam traços de mais um de um sistema gramatical. Por conclusão, define-se o modelo teórico-descritivo como baseado no processo de metaforização e, a partir disso, apresenta-se o conceito de letramento. 


\section{Teorias, modelos mentais e o estudo dos sistemas falados}

$\mathrm{Na}$ ordem comum dos preceitos adotados pela cultura científica, uma teoria se concebe no interior de um sistema fechado de argumentos que lhe dão sustentação, organizando-se de modo a atender a duas premissas básicas:

(a) adequação externa, segundo a qual os elementos que compõem a teoria devam propor explicações tangíveis para os fatos de mundo por ela descritos;

(b) adequação interna, segundo a qual a estrutura da teoria (seus argumentos, variáveis e outros aspectos que lhe dão corpo) deva manter coerência entre suas partes, bem como entre si própria e outras teorias que a antecederam na mesma linha doutrinária.

No caso de algumas teorias, considera-se, ainda, uma outra ordem de adequação, relativa ao seu potencial de explicar fatos que se dêem no processamento mental da gramática, ou seja, na atividade cognitiva responsável pela derivação e pela interpretação de frases, ou textos, conforme a doutrina lingüística. Trata-se de teorias que buscam descrever a estrutura e o funcionamento de fenômenos produzidos pela razão humana, tais como o são, por exemplo, as gramáticas das línguas naturais. Este tipo de fenômeno apresenta um problema fundamental para a ciência, haja vista que sua materialidade não tem existência em si mesma, mas se produz através de operações estritamente cognitivas. Neste sentido, por exemplo, o estudo das gramáticas naturais se desloca do nível descritivo, relativo aos sinais físicos da fala, para se concentrar nos princípios mentais que regem a organização de sentenças ou textos, assim arroladas como gramáticas mentalmente concebidas (Cf.: Chomsky 1965:107-110) ${ }^{1}$. Cabe, então, à teoria explicar como tais gramáticas são construídas e operadas pela própria mente humana, deste modo colocando-a sob a dependência de alguma outra teoria que dê corpo conceitual ao modelo de mente que, supostamente, seria sujeito das operações gramaticais. Ressalve-se que consideramos aqui três conceitos distintos ao tratarmos de mente, modelo mental e modelo descritivo. Dos três, somente o de mente reporta-se a um fenômeno real, próprio do ser humano, ainda que de natureza estritamente simbólica e, por

\footnotetext{
1 No caso de obras traduzidas, os números de páginas citados referem-se às publicações em Português.
} 
este motivo, não analisável a partir dos critérios adotados pelas ciências naturais. $\mathrm{O}$ custo de análise deriva a necessidade de a ciência postular não mais do que hipóteses sobre a estrutura e o funcionamento da mente, no interior das quais derivam-se modelos mentais, ou seja, teorias que têm por objetivo apresentar explicações sobre como deve ser a mente, sua estrutura e seu funcionamento. Já os modelos descritivos são teorias gramaticais que, tendo por fundo um certo modelo mental, visam a explicar como o falante processaria as línguas naturais.

A transferência da figura do sujeito das operações gramaticais para o domínio de um modelo de mente - um protótipo abstrato, portanto, concebido como hipótese acerca de como deva ser a mente a partir de um conjunto de postulados teóricos, igualmente hipotéticos - deve-se propriamente ao fato de que, apesar de todos os esforços acadêmico-científicos, ainda não nos foi possível definir toda a estrutura e o funcionamento da mente humana a ponto de tomá-la como um conceito científico definitivo.

A adequação explicativa, no âmbito da Lingüística, não assume por objetivo avaliar a teoria de mente que está por trás da teoria gramatical, limitando-se a buscar responder, sistematicamente, se os fatos arrolados na sua teoria podem, ou não, ser construídos e operados pelo modelo mental selecionado como parâmetro. Por este motivo, após ter sido introduzida na ciência lingüística, a adequação explicativa não tardou a ser um pouco mais tarde tratada como "condição de aprendizibilidade" (Cf.: Hawkins 1988:5-8), ressaltando-se aí a adequação a um contexto que necessita absorver certo princípio teórico, de forma tão natural quanto a suposta naturalidade com que o modelo de mente o absorveria quando de seu desenvolvimento no ser humano.

Em que pese o rigor acadêmico imposto à teoria pelas três condições de adequação, concretamente, todavia, a adequação interna tende a prevalecer, sob prejuízo da externa. Isto se percebe evidente no caso da adequação explicativa, já que, sob todos os aspectos, centra-se no corpo de outra teoria que é não mais do que uma hipótese sobre a mente humana e não, em evidências empíricas que, não raramente, contrariam as expectativas funcionais do modelo de mente. O que se tem por trás da "condição de aprendizibilidade" nada mais é do que a ponderação sobre ser possível ao modelo $\mathrm{Y}$ de mente absorver o traço $\{a\}$ da teoria $\mathrm{X}$. Ainda que $\mathrm{X}$ e $\mathrm{Y}$ sejam tomados como universos teóricos distintos e autônomos, para que os 
elementos $\left\{\mathrm{a}^{1}, \mathrm{a}^{2}, \mathrm{a}^{3} \ldots \mathrm{a}^{\mathrm{n}}\right\}$ pertencentes a $\mathrm{X}$ possam ser comparados à lógica interna da teoria $\mathrm{Y}$, é preciso, antes de mais nada, que ambas as teorias mantenham uma tamanha uniformidade de princípios e unidades, que $\mathrm{X}$ nada mais passa a ser do que parte de $\mathrm{Y}$. Conseqüentemente, sendo Y a matriz que determina as condições de adequação à formulação de $\mathrm{X}$, esta e todas as suas categorias passam a assumir mais o papel de validar $\mathrm{Y}$, do que, propriamente, analisar e descrever o fenômeno mental que é seu objeto primeiro. É assim, portanto, que teorias podem, ao descreverem fatos sob subordinação a uma teoria mental externa, reduzir o sujeito epistemológico dos fatos analisados a meros robôs do modelo Y, no interior do qual se materializam. $\mathrm{O}$ valor de verdade de teorias desta natureza sustenta-se integralmente nesta relação $(X, Y)$, exigindo-se que se formulem expressões do tipo " $\left\{\mathrm{a}^{\mathrm{n}}\right\} \square \mathrm{X}$ é verdade em $\mathrm{Y}$ ".

Uma formulação do tipo " $\left\{\mathrm{a}^{\mathrm{n}}\right\} \square \mathrm{X}$ é verdade em $\mathrm{Y}$ " demanda que a teoria sustente sua verdade exclusivamente no interior do contexto conceitual (estritamente lógico, portanto) que lhe dá sustentação, nele instituindo cada um dos parâmetros para avaliação de sua adequação. Teorias deste tipo são denominadas - nas ciências da linguagem - como conceptualistas e podem ser exemplificadas por meio do modelo gerativista de gramática proposto na doutrina teórica fundada por Noam Chomsky no século passado (Cf.: Chomsky 1957;1965;1966). No âmbito de tais modelos teóricos, a concepção de alguma adequação externa surge como um paradoxo, à medida que, a priori, sua referência de mundo encontra-se atrelada a uma esfera idealizada de forma abstrata, ou seja, à teoria de mente a que se vincula. Trata-se, assim, de uma externalidade concebida e avaliada no estreito limite que vai de um corpo teórico para outro, ao qual se vincula paradgimaticamente. Maior ainda se torna o paradoxo, quando, devido à força ilocucionária do discurso acadêmico, a externalidade conceitual da teoria conceptualista passa a ser assumida publicamente como externalidade material, transferida para a esfera social, assumindo-se que a esfera pública - em sua dimensão real e não determinada pelas condições de adequação que sustentam a teoria - possam, ou devam, reduzir-se àquela forma concebida no interior da teoria (Cf.: Berticelli 2004:63-78).

A exemplo do que se apresenta de forma aguda e radical nas teorias conceptualistas, os demais corpos teóricos das ciências da linguagem vêm assumindo indiscriminadamente posturas semelhantes para com relação à identidade da realidade material que, supostamente, é arrolada como princí- 
pio de sua adequação externa. Desde o seu surgimento enquanto ciência, a Lingüística vem se posicionando frente a diferentes hipóteses sobre o modo de funcionamento da mente humana, nas quais dá embasamento, até mesmo, às teorias empíricas de descrição gramatical, a exemplo do Estruturalismo Norte-Americano, de base preponderantemente taxionômica e probabilística. Se, por seu turno, o conceptualismo gerativista assume sua natureza ao dispor de um conceito a que denomina "falante/ouvinte ideal" (Cf.: Chomsky 1965), nas correntes estruturalistas as mais diversas, a tendência conceptualista se manifesta através da eleição ou derivação de um certo modelo ideal (ou padrão) de gramática, seja este concebido como um padrão gramatical hegemônico perante um complexo de variantes raramente exploradas no processo descritivo, seja, ainda, pela pré-concepção de uma estrutura conceitual de gramática associada a um só modelo de processamento frasal (a estrutura gramatical determinada na tradição gramatical, sob influência da filosofia aristotélica).

$\mathrm{Na}$ realidade, a estrutura das teorias gramaticais que se empregaram correntemente na Lingüística durante o século passado esteve sempre associada a uma concepção única de estrutura profunda (Cf.: Chomsky 1965:121), à qual se associam, simultaneamente, o conceito de oração e toda a lógica cartesiana com que se explica a sua organização sintática. Deste modo, as teorias gramaticais têm em comum um mesmo modelo de sujeito lingüístico, herdado da concepção filosófica de sujeito científico, traçado na Antigüidade Greco-Romana e socialmente instituído na cultura científica durante o Iluminismo (Cf.: Favero 1996). Tal sujeito científico tem tido preponderância não apenas sobre os estudos gramaticais, mas também, sobre todos os sujeitos potencialmente arrolados na cultura científica, vindo a se estender, inclusive, na idealização de sujeitos sociais, antropologicamente fundados à luz de um modelo cultural instituído à forma preconizada pela Razão acadêmica. O trecho a seguir, bem exemplifica tal relação entre teorias descritivas e sujeitos sociais idealizados: "Uma 'bipótese do Inatismo' geral incluirá, ainda, princípios que repercutem no lugar e papel das pessoas num mundo social, na natureza e nas condiçôes de trabalho, na estrutura da ação, vontade e escolba humanas, e assim por diante, Estes sistemas podem ser em sua maior parte inconscientes e mesmo estar além do alcance da introspeç̧ão consciente. Pode-se também querer tomar isoladamente como um objeto de estudo as faculdades envolvidas em solução de problemas, construção de conhecimento científico, criação e expressão artísticas, jogos, ou qualquer aspecto que se revele categoria adequada para o estudo da capacidade cognitiva e, indiretamente, da ação bumana." (Chomsky 1975:32). 
Nesta perspectiva, mesmo os estudos sobre o discurso - que transbordam as fronteiras da estrutura orgânica da oração - surgem embasados no mesmo sujeito idealizado pela cultura científica, à medida que sua fonte inicial seriam as teorias dos atos de fala, originárias da Filosofia da Linguagem. Ora cartesianos - como os de Searle (Cf.: Searle 1969:27-8) - ora socialmente motivados - como os de Wittgenstein e seus "jogos de linguagem" -, os estudos de filosofia de linguagem vinculam-se historicamente a um só eixo cultural determinante do sujeito lógico moderno. Mais tarde, porém, a partir de contribuições como a de Habermas, a teoria do discurso avança no sentido de superar este sujeito modelar da cultura científica, especialmente a partir do alargamento do conceito de "atos de fala", através da derivação de um outro, mais complexo, chamado "atos comunicativos". À medida que isto se dava, todavia, quanto mais se buscou distanciarem-se os estudos sobre o discurso do modelo lógico de sujeito, tanto menos se buscou arrolar o impacto deste distanciamento sobre o conceito de sujeito subjacente às teorias gramaticais, permitindo-se, deste modo, que a análise do discurso e a teoria da gramática começassem a trilhar caminhos diferentes e não intercomunicáveis durante algum tempo.

Enquanto se consolidavam os estudos sobre a $i$-materialidade social do sujeito lógico, no interior dos estudos acerca dos atos comunicativos, a teoria gramatical começa, já na passagem para o Século XXI, a cotejar um estudo descritivo mais consistente sobre a oralidade, o qual permitiria a superação dos empreendimentos de ordem descritivo-quantitativa, introduzidos pela Sociolingüística Quantitativa de Labov duas décadas antes. Fala a escrita - ou, língua oral e língua escrita - podem, finalmente, ser analisadas como fenômenos materialmente distintos e autônomos entre si, permitindo-se descortinar a natureza gramatical de estruturas textuais planejadas e organizadas por sujeitos, não, alinhados à cultura científica, mas sim, alinhados à ordem da interação sob condições de comunicação específicas da fala, regidas pelo estresse da velocidade e da pluralidade de intenções comunicativas.

A introdução do fator intencionalidade nos estudos gramaticais incorporaria à teoria lingüística aspectos cujo controle não mais se circunscrevia à estrutura interna dos sistemas regidos por regras gramaticais, autorizando-se, finalmente, que os sujeitos falantes fossem tomados como agentes interferentes na estrutura da frase e do texto, movidos pelo interesse maior quanto à satisfação das necessidades de interação com os contextos sociais 
e seus interlocutores, variáveis caso a caso. Inaugurava-se, com isto, uma era em que a fala não reduzir-se-ia a uma estrutura simbolicamente agregada à suposta universalidade da estrutura profunda de base lógico-cartesiana, mas sim, explicar-se-ia a partir de regras e condições a ela específicas, não raramente transportadas para os textos escritos. A intencionalidade tem sido substantivada na teoria lingüística por categorias desenvolvidas pela área de análise do discurso, tais como a adequação discursiva e os gêneros lingüísticos, essencialmente motivadas pela necessidade de se estabelecer uma relação entre o estudo do texto e as dinâmicas produzidas no interior de seus usos em sistemas sociais concretos e específicos. A partir de tais categorias da $\mathrm{AD}$, já se conseguia tratar do sujeito da comunicação como plural, ou seja, como uma categoria que se institui no próprio ato comunicativo, não podendo ser reduzida a modelos predeterminados.

Os estudos sobre a gramática da língua falada - este sistema complexo e sempre sujeito às intenções dos falantes - deflagram a necessidade de se arrolarem novos sujeitos teóricos para além da figura constante e ahistórica do sujeito da cultura científica, a exemplo do movimento assumido pela análise do discurso no estudo das categorias sociais do texto. Neste sentido, a busca por um novo modelo cognitivo para a mente humana, passa a confundir-se com a busca do sujeito objeto da lingüística, do mesmo modo que, no passado, a busca de um tal sujeito confundira-se com as múltiplas hipóteses sobre a mente cartesiana. O problema da conceituação do processo de letramento situa-se no entorno deste mesmo sujeito teórico, ainda por se construir na Pós-Modernidade, motivo pelo qual tratar-se de uma discussão que deve caminhar em paralelo às discussões sobre modelos teóricos de gramática, que dêem sustentação à descrição acadêmica do sistema gramatical da fala, e sobre modelos mentais, que dêem sustentação àquela.

\section{Modos do pensamento e processo de letramento}

O princípio fundamental a ser atendido na formulação do conceito de letramento consiste em se permitir a aplicação de parâmetros de adequação externa confrontáveis aos sujeitos não idealizáveis do letramento escolar, instituídos a partir de sua pluralidade e socialmente construídos com base na complexidade de fatores que os tornam usuários de línguas orais e não, de línguas redutíveis à forma como a cultura científica idealizou a 
escrita. A relação do processo de letramento com a Educação - e suas práticas sociais específicas - exige-nos, ainda, que tomemos como necessária a adoção de princípios para avaliação do conceito em termos de sua adequação explanatória, à medida que o modelo de funcionamento da mente plural deste sujeito, de base marcadamente oral, funciona como parâmetro fundamental adotado pelas escolas para fins de planejamento e de avaliação do desenvolvimento do aluno em formação. A possibilidade de um posterior diálogo entre a teoria do letramento e as teorias de aprendizagem que dão conformação ao sujeito escolar torna-se imprescindível, sob pena de se vir a formular um conceito de letramento que não possibilite sua integração ao contexto escolar de forma coerente e integrada ao seu projeto político-pedagógico - especialmente, quando a própria escola passa por um processo de redefinição social, no qual procura situar-se diante de sujeitos que não mais buscam conformar-se ao modelo de cidadão ditado pela cultura científica.

As diferenças entre a materialidade das falas possíveis nos contextos comunicativos e a da escrita, ao mesmo tempo vinculadas às distintas condições de produção e às especificidades gramático-discursivas de cada uma, sugerem aspectos extremamente relevantes para a discussão do conceito de letramento. A legitimação da estrutura potencial da fala como fenômeno autônomo e distinto da escrita já nos permite levantar uma objeção $a$ priori ao clássico entendimento de que a função escolar do letramento restrinja-se às práticas de alfabetização, tomadas desde si mesmas, tal como em condutas especificamente destinadas ao ensino do código escrito. Isto não significa dizer que a alfabetização esteja alijada do processo de letramento, porém, tão somente, que este não se reduz apenas à alfabetização.

O grande problema subjacente à crença em um letramento associado exclusivamente à alfabetização reside justamente no fato de que o acesso à escrita envolve muito mais do que o simples acesso a um código alfabético. O domínio da escrita implica dominar um modo particular de produção textual, não equivalente ao envolvido na produção da fala. Ao se restringir o letramento ao processo de construção do código escrito, despreza-se o fato de que o sujeito social da fala não necessariamente é o sujeito social da escrita, vinculando-se, a partir daí, todas as práticas de ensino da escrita a um único sujeito, potencialmente equivalente ao sujeito universal da cultura científica, estritamente lógico. 


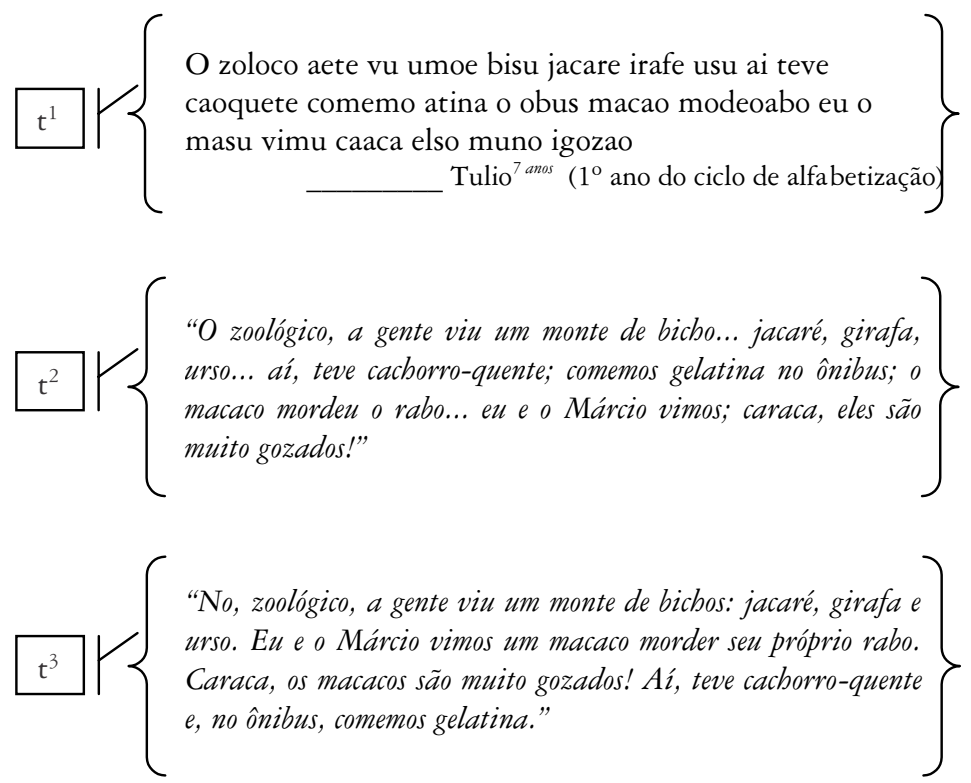

Os textos $\mathrm{t}^{1}, \mathrm{t}^{2}$ e $\mathrm{t}^{3}$ são versões gráficas diferentes de um mesmo texto oral que poderia ter sido transcrito na forma como, a seguir, em $t^{0}$ :

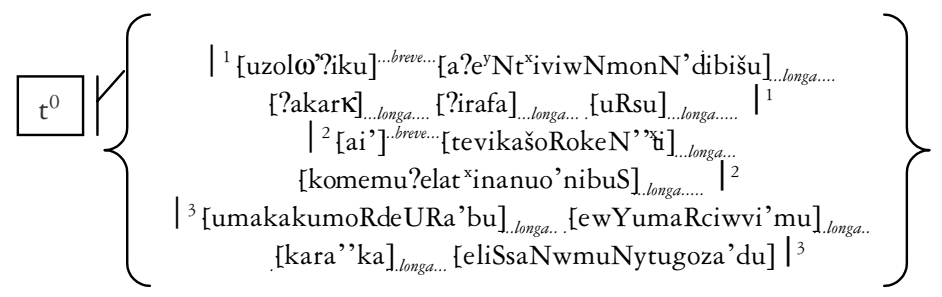

Observando-se a forma expressa em $t^{0}$, pode-se verificar que $t^{1}, t^{2}$ e $t^{3}$ situam-se em diferentes pontos de um gradiente que vai desde a mera transcrição alfabética da fala $\left(t^{1}\right)$, até uma forma gráfica especificamente organizada segundo as regras da língua escrita $\left(t^{3}\right)$. Tradicionalmente, o percurso de $t^{1}$ a $t^{3}$ tem sido arrolado como uma série de etapas do processo de alfabetização (cf. Kato 1995), em que se toma por parâmetro o modelo final de $t^{3}$ como comportamento esperado do aluno. O tratamento clássico da construção da escrita arrola as diferenças estruturais observáveis em $t^{1}$, 
$t^{2}$ e $t^{3}$ como fenômenos de ordem ortográfico-gramatical a serem superados em favor da estrutura orgânica da língua escrita.

Assim é, portanto, que um sujeito autor de textos do tipo de $\mathrm{t}^{1}$ é considerado não alfabetizado, ao passo que sujeitos autores de textos como $\mathrm{t}^{2}$ e $\mathrm{t}^{3}$ são considerados alfabetizados, por manifestarem comportamentos gráficos que superam o custo imediato de se aplicar à escrita a estrutura orgânica da fala. Fato é, todavia, que a diferença básica entre $t^{1}$ e $t^{2}$ reside tão somente na forma ortográfica e na delimitação das fronteiras de palavras e unidades frasais, não chegando a caracterizar propriamente a diferença entre um sujeito não alfabetizado e um sujeito alfabetizado. Apesar de satisfazerem as regras ortográficas e sintático-frasais da escrita, $t^{2}$ e $t^{3}$ não são equivalentes quanto ao nível de adequação à produção da escrita, à medida que fatores outros - de natureza extra-frasal, somente atendidos em $\mathrm{t}^{3}$ - concorrem para que se satisfaçam as condições de uso da língua escrita, relativamente à ordenação e à articulação dos fatos expressos (observe-se, por exemplo, o deslocamento de "Aí teve cachorro-quente e comemos gelatina no ônibus" em $\mathrm{T}^{3}$ ).

Ao se observar $\mathrm{t}^{1}$ e $\mathrm{t}^{2}$, torna-se claro que o conceito de letramento deva situar-se muito para além da simples concepção de aquisição do código alfabético da escrita, deixando por terra a memória consagrada na cultura escolar e acadêmica de que se possa desenvolver a escrita tão somente a partir de estratégias de desenvolvimento do código alfabético. Dadas as significativas diferenças entre as condições de produção da comunicação oral e as da escrita, tomar do letramento como um mero processo de transcodificação poderia resultar, quando muito, em padrões de comportamento tal como expresso em $\mathrm{t}^{2}$, situado no meio do caminho entre a fala e a escrita. Metodologias clássicas de alfabetização - tal como nos métodos fônicos ou gestálticos (p. ex., a palavração) - incorrem necessariamente em estados de semi-letramento, ainda que possam ser bem sucedidos, em alguns casos, no processo de descoberta da funcionalidade do código alfabético.

O problema apresentado no gradiente exemplificado nos textos $\mathrm{T}^{1} \mathrm{a}$ $\mathrm{T}^{3}$ não se explica a partir de um maior ou menor domínio quanto ao uso funcional do código alfabético, mas sim, do maior ou menor entendimento sobre as condições de produção da fala e da escrita no momento em que se utiliza do código escrito para produzir textos. A questão que se coloca, então, é como definir os fatores que intervêm na construção de um tal 
entendimento sobre as diferenças nas condições de produção da fala e da escrita. Trata-se de uma questão imperativa, já que, uma vez superado o conceito clássico de alfabetização (enquanto processo de construção do código escrito), o letramento deve estar associado a um processo decisório no qual o sujeito opta, conscientemente, por empregar estratégias discursivas, ora mais, ora menos, associadas às condições da fala ou da escrita. A concepção de um processo decisório vinculado ao conceito de letramento, leva em consideração o fato de que as condições de produção da escrita há muito ultrapassaram os limites impostos pela relação do homem com o papel, autorizando os sujeitos a interagirem - através do código alfabético - em ambientes virtuais, em que as condições de produção mesclam-se entre as da escrita e as da fala. Neste sentido, por exemplo, alguns textos ortograficamente alienados do padrão ortográfico da escrita são absolutamente adequados, quando empregados em contextos virtuais, como os chats, nos quais o processamento da escrita demanda uma velocidade muito maior do que quando projetada para o papel. Deste modo, do ponto de vista ortográfico, um texto como $t^{4}$ acabaria situando-se muito mais próximo de $t^{1}$ no gradiente $\left\{\begin{array}{lllll}t^{1} & O & t^{4} O & t^{2} O & t^{3}\end{array}\right\}$. No entanto, não se pode atestar de modo algum que se trate de um texto inadequado às condições de produção em uma sala de chat, pelos fatores que se analisam adiante.

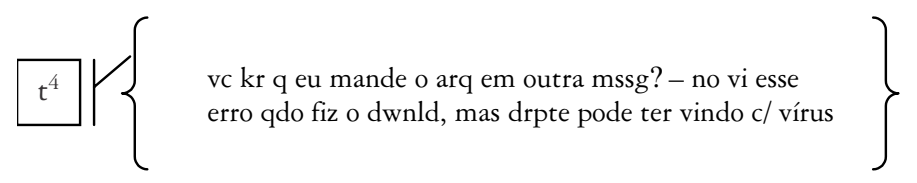

Três das diferenças mais significativas entre as condições de produção da fala e da escrita consistem, respectivamente, na modalidade de interação, no tempo de processamento e no processo de objetivação do tema. $\mathrm{Na}$ escrita, a interação dá-se com um sujeito potencialmente ausente, ainda que desenhado como um interlocutor em potencial, cuja interação não ocorre durante o processamento do texto. $\mathrm{Na}$ fala, por sua vez, a interação é simultânea e frente a um sujeito que pode, a qualquer tempo, intervir no processamento textual, tornando-se co-autor de um texto cujo sentido se constrói na intenção comunicativa que se estabelece na relação \{emissor I receptor $\}$. Esta relação de reciprocidade não se dá no processamento da escrita, no qual prevalece a relação $\{$ emissor 0 receptor $\}$. Em conseqüên- 
cia desta relação de reciprocidade na produção da fala, o tempo de processamento torna-se muito rápido, a fim de que se atenda a expectativa pela participação simultânea de ambos, receptor e emissor, na tecitura do texto. A tensão provocada pela relação entre o emissor e o receptor torna-se praticamente neutra na produção da escrita, possibilitando um tempo de processamento mais lento e regido integralmente pelas expectativas e características do próprio emissor. Entretanto, quanto maior a opacidade quanto à figura do interlocutor ao qual se destina o texto, maior a estranheza do processo comunicativo, exigindo-se do emissor, por conseguinte, o desenvolvimento de uma postura comunicativa igualmente estranha, baseada no estabelecimento de um interlocutor a priori, meramente lógico no ato da escritura, com o qual não se conta para compartilhar da construção do texto. Resta-lhe, portanto, num contexto comunicativo como esse, interagir consigo mesmo, exercitando compartilhar, ao mesmo tempo, o lugar do emissor e o lugar do outro, seu receptor potencial. Comparado às condições de produção da fala, a conduta de ocupar ao mesmo tempo o lugar de si e do outro materializa-se como "falar sozinho", algo que, como bem sabemos, não costuma ser bem avaliado pelo senso comum. Observese, portanto, que, no transcurso do processo de letramento, o desenvolvimento deste sujeito em ausência é um custo adicional à construção da escrita.

A terceira diferença resulta das duas anteriores, apresentando, porém, uma questão ainda mais complexa para a problemática do letramento. Toda comunicação envolve um tema, que perpassa as intenções de interação entre o emissor e do receptor e que, em primeira instância, institui a finalidade do texto. As distintas condições da fala e da escrita associam-se, também, a distintos modos de objetivar o tema da comunicação, antes mesmo de se definir a forma a ser dada ao texto. A objetivação do tema pode ser definida como o processo através do qual o sujeito define para si mesmo e para o seu interlocutor o objeto da comunicação. Tal objeto, por sua vez, não se pode definir como um fenômeno exclusivamente lógico, dissociado de todos os aspectos fenomenológicos que concorrem para sua conceituação, seja em nível sócio-cultural, afetivo, ou contextual, considerada a complexidade de fatores que, somente quando tomados em conjunto, dão sentido conceitual às coisas do mundo. A objetivação do tema da comunicação é, por si, um ato de leitura de mundo (cf. Senna 1999), um ajuizamento pessoal de fatos representados e subjetivados na mente de cada sujeito. 
Fala e escrita arrolam, respectivamente, diferentes formas de objetivação do tema, o que, em outros termos, vale o mesmo dizer que operam diferentes modos de leitura de mundo. $\mathrm{Na}$ fala, o estresse provocado pelo tempo de processamento e a perspectiva de compartilhamento da construção do texto com o interlocutor autorizam os sujeitos a operarem a objetivação do tema com um nível de planejamento muito baixo. O contrário se dá na escrita, com um nível de planejamento muito elevado e, daí, uma objetivação bem mais minuciosa do tema. Maior e menor níveis de planejamento textual costumam ser tratados nas ciências da linguagem como fatos associados à estruturação e leitura de categorias gramaticais, tal como quando, nos estudos sobre coesão textual, analisam-se, por exemplo, as diferenças entre as categorias e as regras de pronominalização específicas de textos orais e escritos. A questão da objetivação do tema antecede, contudo, a problemática estrutural do texto, muito mais relacionando-se a mecanismos gerais de estruturação do pensamento.

Ainda que a estrutura central da cognição humana seja de natureza universal - e com isto faço cá reiterar que o potencial cognitivo não é um dom garantido a uns e negado a outros, mas sim, uma estrutura presente na própria condição humana -, os sujeitos não são universalmente programados para dispor da cognição de uma única forma. O caso dos níveis de planejamento no processo de objetivação de um tema é um bom exemplo disso. É possível tratar-se de, pelo menos, dois modos diferentes de operação cognitiva relativamente ao ajuizamento dos fatos do mundo, respectivamente associados a diferentes níveis de planejamento: um que resulta em textos com formato oral (tal como na fala) e outro que resulta em textos com formato escrito (tal como na escrita alfabética). Apesar de tais níveis distintos de planejamento refletirem-se na forma dos textos oral e escrito, sua natureza não é lingüística, tampouco discursiva, mas sim, cognitiva, pois que decorre do modo como o sujeito opera suas funções mentais. Esta é uma observação das mais pertinentes, pois nos alerta para o fato de não se tratar de algo vinculado exclusivamente ao comportamento comunicativo do sujeito e sim, algo que se vincula a toda e qualquer atividade praticada pelo sujeito com a intervenção de sua mente, ou seja, praticamente tudo o que faz, consciente ou inconscientemente, excetuando-se suas funções autônomas de base intuitiva. 


\section{Intencionalidade, modos do pensamento e a teoria da gramática}

O reconhecimento de dois modos distintos de pensamento, cada qual associado a um modo de leitura de mundo, traz-nos um problema particularmente desconcertante para a teoria lingüística, tendo em conta a questão de sua adequação explicativa. Cada modo de pensamento determina um tipo de texto e cada um destes organiza-se com base em condições específicas de produção e, ainda, a partir destas, em torno de regras frasais e textuais igualmente específicas. Uma hipótese viável para que se possa dar sustentação explicativa a alguma teoria seria a de vinculá-la a um dos modelos e, deste modo, utilizá-la para dar conta do sistema de comunicação a ele vinculado. Isto nos traz de volta formulações do tipo " $\left\{\mathrm{a}^{\mathrm{n}}\right\} \square \mathrm{X}$ é verdade em Y", tal que Y é o modelo de mente que opera para produzir textos na língua $\mathrm{X}$. Desta feita, porém, X é tão somente um fragmento no universo de línguas que um mesmo sujeito pode operar, já que em outros estados de mente o sistema $\mathrm{X}$ não seria gerado, ou geraria textos inadequados. Decretar-se-ia, portanto, a falência conceitual da lingüística enquanto ciência das línguas naturais, já que sua função jamais alcançaria a possibilidade de estar postulando princípios universais e generalizantes sobre a natureza e a funcionalidade da língua humana.

Avançando na análise da questão referente ao letramento, podemos acrescentar questões que poderão contribuir para a superação do casuísmo e da fragmentação ora imposta à teoria gramatical. Com base na hipótese levantada no parágrafo anterior, a descrição lingüística poderia se dar na forma de uma série de teorias respectivamente associadas a determinados modos do pensamento humano. Cada teoria $\mathrm{T}$ teria vigência sobre o conjunto de textos $\left\{. . \mathrm{t}^{\mathrm{n}} \ldots\right\}$ empregados sob a regência de um modo $\mathrm{M}$ do pensamento do humano, $\mathrm{H}$. Isto pode ser expresso na forma de...

I $\quad-\left\{\mathrm{t}^{\mathrm{n}}\right\} \square \mathrm{T}^{\mathrm{n}}$ regido por $\mathrm{M}^{\mathrm{n}}$ em $\mathrm{H}$

II $-\left\{t^{\mathrm{n}}\right\} \square \mathrm{T}^{\mathrm{Zn}}$ regido por $\mathrm{M}^{\mathrm{Zn}}$ em $\mathrm{H}$

A verificação de I e II acima somente se sustentaria verdadeira se $\mathrm{H}$ fosse um sujeito passivo frente aos modos de operação de seu próprio pensamento. Se assim o fosse, uma vez operando sobre um modo M do pensamento, $\mathrm{H}$ geraria tão somente textos na língua T equivalente. Os textos $\mathrm{t}^{1}$, $t^{2}$ e $t^{4}$ são, entretanto, prova de que isto não se dá, pois todos se situam em 
uma faixa de transição entre as propriedades do sistema $\mathrm{T}$ regido pelo modo oral e as de $\mathrm{T}$ regido pelo modo pensamento responsável pela escrita. A partir disso, ainda que a lingüística optasse por se satisfazer com uma estrutura de teorias especializadas em modelos mentais isolados, sua capacidade de obter adequação externa estaria invariavelmente comprometida, já que inúmeros textos compartilham propriedades oriundas de diferentes modelos gramaticais. Do mesmo modo, um conceito de letramento que se sustente tão somente no fato de que as línguas oral e escrita sejam regidas por sistemas diferentes não se tornaria adequado, uma vez que, além das interferências de um sistema sobre o outro (tal como em $\mathrm{t}^{1}$ e $\mathrm{t}^{2}$ ), há situações comunicativas em que somente a confluência de sistemas é capaz de provocar adequação a certas condições comunicativas (tal como em $\mathrm{t}^{4}$ ).

A existência de contextos de confluência com propriedades de diferentes modos do pensamento sugere ser de todo inadequada a opção por estratégias descritivas que se concentrem em modelos gramaticais especializados a um ou outro modos do pensamento. Vale dizer, portanto, que a teoria gramatical não deve ater-se a modelos mentais especialistas, mas sim, a um modelo de mente que pressuponha as diferentes especialidades, delas dispondo segundo princípios determinados em $\mathrm{H}$, ou seja, a mente regida pelas intenções do sujeito. Isto significa que as condições de adequação externa da teoria estariam condicionadas a parâmetros de adequação explicativa determinados em função do potencial de $\mathrm{H}$ para dar conta das intenções comunicativas, ora determinadas pela oralidade, ora pela escrita, ora por ambas. Assim sendo, a melhor formulação de I e II anteriormente propostas poderia ser obtida através de III, tal como:

$$
\text { III }-\left\{\mathrm{t}^{\mathrm{n}}\right\} \square\left\{\mathrm{T}^{1}, \mathrm{~T}^{2} \ldots \mathrm{T}^{\mathrm{n}}\right\} \text { regido por }\left\{\mathrm{M}^{1}, \mathrm{M}^{2} \ldots \mathrm{M}^{\mathrm{n}}\right\} \text { em } \mathrm{H}
$$

A formulação de III exclui da teoria a possibilidade de impertinência de qualquer texto, à medida que quaisquer formas produzidas em $\mathrm{H}$ estariam necessariamente regidas por algum estado mental $\mathrm{M}$ devidamente instrumentalizado para gerar textos. Isto, conseqüentemente, implica que a avaliação de qualquer $\left\{\mathrm{t}^{\mathrm{n}}\right\}$ passa a estar associada, não a sua forma estruturante, mas, a sua adequação comunicativa, regida, ao mesmo tempo, pelas intenções de $\mathrm{H}$ e pelos contextos de uso, estes últimos somente avaliáveis caso a caso, na interação com o outro da comunicação. Indo do universal ao particular, uma formulação teórica embasada em III explica- 


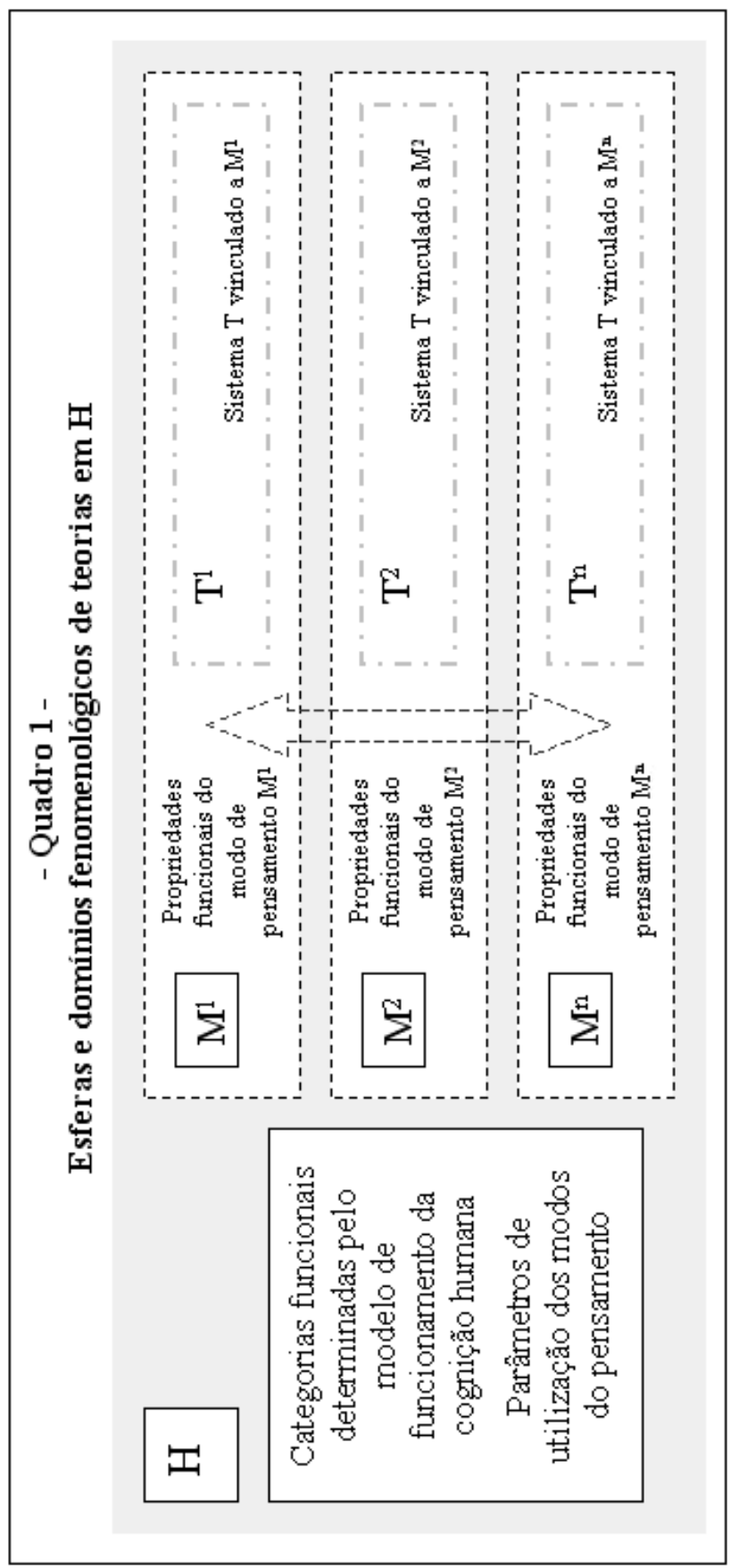


ria, de certo modo, o motivo que teria levado a teoria lingüística a sofrer a cisão ocorrida, no passado, entre estudos gramaticais e estudos sobre o discurso. O deslocamento dos aspectos universais da lingüística para o domínio de $\mathrm{H}$ (regido por parâmetros determinantes das condições de satisfação das intenções comunicativas) permite, ao mesmo tempo, que as flutuações entre os diversos sistemas $T$ possam ser explicadas em termos gramaticais e que tais flutuações possam ser avaliadas externamente, sem prerrogativas determinadas por condições de adequação interna em cada sistema $\mathrm{T}$, mas a partir das condições impostas pelas interações sociais de $\mathrm{H}$ com os demais sujeitos da comunicação.

As categorias de uma teoria dominada por $\mathrm{H}$ exigem, todavia, um deslocamento fenomenológico, à medida que as categorias instituintes normalmente agregadas às próprias condições de adequação de cada siste$\mathrm{ma} \mathrm{T}$ provocam constrangimentos à possibilidade de o sujeito intervir em sua utilização, impedindo, portanto, que textos como $t^{4}$ possam ser gerados. Embora as condições de funcionamento de cada $T$ possam ser explicadas a partir de sua vinculação às propriedades dos modos do pensamento M, cada um destes, isoladamente, não é teoricamente capaz de explicar fenômenos de confluência, tal como expresso em $\mathrm{t}^{4}$, motivo pelo qual a mera expansão do domínio de categorias de $\mathrm{T}$ para $\mathrm{M}$ não resultaria em efeito favorável à obtenção de adequação externa. O fato é que cada modo do pensamento $\mathrm{M}$ funciona como uma ferramenta para $\mathrm{H}$, em cujo domínio parte das propriedades de cada modo pode ser empregada na configuração de um texto, em detrimento de seu arranjo e coerência internos. Em razão disto, uma teoria lingüística sobre textos empregados na comunicação deve buscar dar conta de diferentes esferas de objetos fenomenológicos, tal como se apresenta a no Quadro 1.

Os domínios de categorias apresentados no Quadro 1 nos fazem reportar ao clássico debate entre Jean Piaget e Noam Chomsky, à época em que a concepção de modos do pensamento ainda se iniciava a desenhar na comunidade acadêmica. Defendiam, então, Piaget e Chomsky duas alternativas aparentemente inconciliáveis de explicação para os fatos da mente, em particular os fenômenos ligados à produção de línguas naturais, ambas inatistas, porém diferenciadas quanto à existência, ou não, de núcleos de conhecimento especialista, agregados à concepção radical de Inatismo, tal como defendida na epistemologia de Kant e Humboldt. Por um lado, argüiu Chomsky em favor de um inatismo expresso na forma da modulari- 
dade da mente (cf. Chomsky 1975), no qual se sustentara a concepção de um conceito de universais lingüísticos, tal como uma espécie de matéria prima inata especializada na construção de sistemas gramaticais. Por outro lado, Piaget defendia a universalidade dos sistemas cognitivos, sustentando-se em uma concepção de mente instituída a partir de um núcleo fixo e comum de propriedades operacionais, que daria conta das construções epistemológicas sem demandar módulos especializados.

À primeira vista, o debate entre Piaget e Chomsky estaria concentrado propriamente na defesa, ou de teorias mentais genericamente vinculadas a categorias em $\mathrm{H}$, ou de categorias especialistas, vinculadas aos sistemas T. Ocorre, todavia, que no sistema cognitivo arrolado como matriz de toda a discussão travada por Piaget e Chomsky não se previra a existência de nenhum outro modo de pensamento que não o modelo científico traçado no interior da cultura acadêmico cartesiana, aquele, portanto, que se materializa na forma do sistema do texto escrito, tal como em $\mathrm{T}^{3}$. Disto resultou o impasse nas discussões, pois é impossível explicar a partir do modo científico do pensamento, ao mesmo tempo, (i) como a criança é capaz de desenvolver o sistema da língua sem dispor de aparato cognitivo já plenamente desenvolvido para operar logicamente, tampouco (ii) como o sistema $\mathrm{T}$ logicamente determinado pode gerar textos aparentemente desvinculados de tal sistema lógico, sem perda de potencial comunicativo. Assim, portanto, é que a solução do impasse somente se poderia vir a obter quando se passasse a conceber a mente como um sistema que gera múltiplos sistemas regidos por diferentes modos do pensamento, todos regidos por um mesmo eixo de propriedades dominadas por $\mathrm{H}$. Jamais haveria uma solução para o impasse entre Piaget e Chomsky, já que, na realidade, ambos estavam absolutamente corretos. A existência de universais lingüísticos é uma verdade, conforme muito bem defende Chomsky. Por outro lado, a existência de uma mente que dispõe sobre o uso de tais universais também é verdade, conforme argumenta Piaget. Entretanto, é verdade, também, que diferentes sistemas de operação cognitiva interferem na forma como o sujeito estrutura o texto, exigindo-se da teoria que o descreva observar a existência de diferentes sistemas em constante processo de mútua interferência.

$\mathrm{Na}$ realidade, todo o impasse gerado no século passado decorreu da tentativa de se reduzir o domínio $\mathrm{H}$ a um só modelo de mente $\mathrm{M}$, a despeito de todos os demais modelos $\mathrm{M}^{\mathrm{n}}$ com que a mente humana é capaz de 
operar. Embora se possam estudar tais modos do pensamento como modelos específicos, é impossível tratar $\mathrm{H}$ ou cada sistema $\mathrm{T}$ como modelos teóricos específicos e isolados da complexidade que ocorre quando os diversos modelos $\mathrm{M}$ se fundem, seja na construção de textos estruturados a partir de categorias de vários $\mathrm{M}$ (como no caso dos textos $\mathrm{T}^{0}$ a $\mathrm{T}^{4}$ ), seja na regência de $\mathrm{H}$ sobre os modelos $\mathrm{M}$, deles dispondo sem delimitar suas fronteiras (como no caso das especificidades aplicadas ao texto pelas diferentes intenções comunicativas). Desprezar tal complexidade somente leva ao impasse, tanto diante de comportamentos mentais absolutamente ilegíveis à luz de $\mathrm{H}$, como diante de textos ilegíveis à luz de $\mathrm{T}$. $\mathrm{O}$ valor de verdade de cada texto $\left\{\mathrm{t}^{\mathrm{n}}\right\}$ é determinado e validado, não pelas regras de um sistema a priori, mas sim, pelo arranjo de sistemas $\mathrm{T}$ que o sujeito produz segundo parâmetros determinados em $\mathrm{H}$, a partir de propriedades funcionais de um ou mais modos do pensamento. Por sua vez, nenhum sistema $\mathrm{H}$ opera com parâmetros cuja funcionalidade esteja dominada por um único modo $\mathrm{M}$ do pensamento, de forma que todo sistema de valor gerado em $\mathrm{H}$ perpassa arranjos no conjunto de sistemas cognitivos $\left\{\ldots \mathrm{M}^{\mathrm{n}} \ldots\right\}$.

\section{Sistemas metafóricos e o conceito de letramento}

O problema descritivo que se impõe à teoria da gramática quando se autoriza a $\mathrm{H}$ ter preponderância no uso dos modos do pensamento e dos sistemas $\mathrm{T}$ é o de estabelecer princípios que permitam explicar a criação e a interpretação de textos como $\mathrm{T}^{1}, \mathrm{~T}^{2}$ e $\mathrm{T}^{4}$. A estratégia descritiva a se aplicar a estes textos não pode resumir-se à aplicação das regras que regeriam, por exemplo, $T^{0}$ e $T^{3}$ (respectivamente, produtos do sistema da língua oral e do da língua escrita) cujas estruturas atendem, cada qual, a um único modo do pensamento $\mathrm{M}$. À medida que $\mathrm{T}^{1}, \mathrm{~T}^{2}$ e $\mathrm{T}^{4}$ são plenamente adequados às situações comunicativas em que são aplicados, torna-se profundamente indesejável que os tomemos, na descrição gramatical, como parcialmente adequados ao sistema que rege a fala e parcialmente adequados ao que rege a escrita. Também é indesejável buscar-se a solução do problema postulando a existência de um único sistema $\mathrm{T}$, que, apesar de formado a partir da reunião de propriedades de diferentes sistemas, pudesse ser tratado como independente dos demais. Uma tal solução tornar-seia igualmente indesejável por onerar em muito a teoria da gramática, à 
medida que se teria de postular a existência de um sistema $\mathrm{T}$ particular a cada texto empregado em um ato comunicativo.

Fato é que, em que pese o aparente desarranjo dos sistemas originais em $\mathrm{T}^{1}, \mathrm{~T}^{2}$ e $\mathrm{T}^{4}$, sua estrutura não provoca custo ao falante. Tal como no caso do emprego metafórico de itens lexicais, o falante é capaz de resgatar a funcionalidade de um sistema gramatical que se apresenta metaforicamente construído com partes de sistemas conhecidos. Neste caso, justificase a existência de textos como estes, aqui considerados, não como produtos de algum novo sistema $\mathrm{T}$, mas sim, de um processo de aproximação de sistemas já instituídos, por meio de um mecanismo a que se pode denominar processo de metaforização.

A perda de critérios de validação a priori, seja nas teorias T, seja nas teorias em $\mathrm{H}$, ilustra um contexto em que a metaforização constitui-se como um elemento primordial, através do qual as condições de adequação - não regidas por qualquer lógica a priori determinante - são obtidas a partir de intenções de $\mathrm{H}$ sobre todos os sistemas por ele regidos, tanto em $\left\{\ldots \mathrm{M}^{\mathrm{n}} \ldots\right\}$ quanto em $\left\{\ldots \mathrm{T}^{\mathrm{n}} \ldots\right\}$. Tal processo metafórico a reger a teoria que descreve $\mathrm{H}$ e todos os domínios por ele regidos, explica, tanto fenômenos como $t^{4}$, como todos os fenômenos verificados nos textos produzidos por sujeitos em processo de formação escolar, tais como $t^{1}$ e $t^{2}$, os quais conseguimos, então, tratar como fenômenos legitimamente produzidos por $\mathrm{H}$ e não, como produtos deficitários frente a sistemas aleatoriamente escolhidos como hegemônicos.

As construções geradas em $\mathrm{H}$, perpassadas pela metaforicidade decorrente da confluência de sistemas mentais, nos sugerem a pista para formular o conceito de letramento.

No transcurso dos estudos sobre a alfabetização, Emilia Ferreiro e Ana Teberosky trariam contribuições extremamente relevantes para a superação de impasses como o aqui descrito, entre Piaget e Chomsky. Valendo-se de uma concepção de mente regida por intenções de socialização, a partir do modelo epistemológico descrito por Lev Vygotsky, Ferreiro e Teberosky introduzem uma teoria em que a escrita poderia ser explicada como uma construção regida em $\mathrm{H}$. Todavia, em sua teoria, $\mathrm{H}$ continua sendo descrito como um domínio estruturado a partir de um único sistema $\mathrm{M}$, deste modo exigindo-se que o sujeito alfabetizando partisse para a construção da 
escrita com base em parâmetros exclusivamente dominados por um único modo $\mathrm{M}$ de pensamento, gerador de um único sistema $\mathrm{T}^{\text {escrita }}$.

É com base nesta concepção de mente organizada por um único modo $\mathrm{M}$ de pensamento que a teoria da psicogênese da língua escrita admite como premissa que todo sujeito $\mathrm{H}$ já detém hipóteses sobre a estrutura do código escrito e sobre sua funcionalidade no sistema de comunicação empregado na cultura a que o sujeito está vinculado. Ocorre, entretanto, que isto não é fato. Sujeitos formados em culturas que não privilegiam o modo do

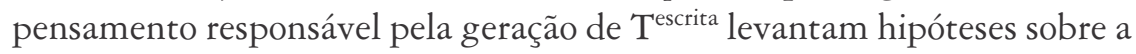
escrita que não os conduzem a $\mathrm{T}^{\text {escrita }}$ e sim, a sistemas metafóricos, situados entre dois ou mais sistemas, formados segundo princípios determinados por vários modos do pensamento mesclados. A distribuição de diferentes

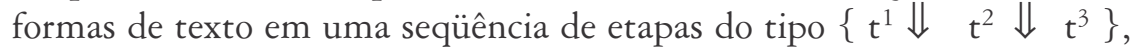
concebidas, como na psicogênese, etapas consecutivas e naturalmente superadas pelos sujeitos alfabetizandos, somente se sustenta se o domínio $\mathrm{H}$ deste sujeito estiver objetivamente buscando conhecer $\mathrm{t}^{3}$ como parte do sistema $\mathrm{M}$ a ele correspondente. De outra forma, ou seja, não se estando em busca de $\mathrm{M}^{\text {escrita }}$ que gera $\mathrm{T}^{\text {escrita }}$, o alfabetizando permanece derivando hipóteses que não o conduzem à escrita, mas sim, a estruturas permanentemente metafóricas, ora mais, ora menos próximas do código escrito.

Os chamados analfabetos funcionais - ou seja, aqueles que se utilizam do código escrito de forma não equivalente àquela que se espera de usuários que dominem o sistema $\mathrm{T}^{\text {escrita }}$ - resultam de práticas de alfabetização que os introduziram à tecnologia da escrita alfabética sem lhes proporcionar o desenvolvimento do modo do pensamento que dá conformação material à escrita. Os analfabetos funcionais não são sujeitos deficitários, cuja

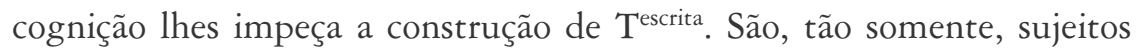
cuja cognição, organizada em $\mathrm{H}$, satisfaz-se com interações comunicativas e com leituras de mundo que não envolvem o emprego do modo do pensamento $\mathrm{M}^{\text {escrita }}$, ao qual se poderia denominar, modo científico do pensamento. Não se trata, portanto, de um comportamento que se reflita apenas na produção escrita do sujeito, mas em todos os estados de interação com o mundo, incluindo as experiências de leitura de mundo, sua percepção (psicomotora) e sua conceituação (sócio-afetiva), todos vinculados às intenções que o sujeito imprime em sua relação com o outro e consigo mesmo.

O conceito e o processo de letramento não se restringem à construção da escrita, muito ao contrário, situam-se na esfera do desenvolvimento 
humano, ao mesmo tempo, em $\mathrm{H}$, nos diversos modos do pensamento em $\left\{\ldots \mathrm{M}^{\mathrm{n}} \ldots\right\}$ e nos diversos sistemas $\left\{\ldots \mathrm{T}^{\mathrm{n}} \ldots\right\}$, sempre em busca de alternativas de expressão adequadas às circunstâncias da produção de conceitos e da comunicação. Neste sentido, o letramento pode ser definido como o processo de desenvolvimento de habilidades para operar sistemas $\mathrm{T}$ em diferentes modos do pensamento, segundo determinações definidas por diferentes intenções comunicativas.

Como as diferentes intenções dos sujeitos são condicionadas à forma como estes se situam na sociedade, o letramento é um processo que:

a) persiste durante o período de vida do sujeito, levando-se em conta que as diferenças etárias e as mudanças nas esferas sociais provocam diferentes formas de interação e, conseqüentemente, demandam diferentes formas de operações mentais, cada qual derivando diferentes tipos de textos;

b) interfere em todo o sistema de valores do sujeito, envolvendo, portanto, sua relação como todos os modos do pensamento e todos os sistemas $\mathrm{T}$ possivelmente empregados pelo homem, de modo tal que constitui-se como um processo que interfere, tanto sobre a construção da escrita, quanto sobre o desenvolvimento de múltiplas formas de expressão oral, lógico-abstrata (através do emprego de sistemas simbólicos de base lógica, como nas matemáticas), artística e tantos outras;

c) é, portanto, interdisciplinar (cf. Santomé 1998), quando tomado como um processo que interfere sobre os sistemas simbólicos humanos e em sua operacionalidade global, e multidisciplinar, quando tomado como esforço coletivo de diferentes agentes sociais, envolvidos, cada qual, com um tipo específico de interação com o mundo.

O conceito de letramento ora traçado pressupõe mais do que um mero arranjo conceitual de esferas de categorias em uma dimensão lógico-conceitual. Por trás de si, há, propriamente, a incorporação de um modelo epistemológico de cognição que interfere materialmente sobre toda a iniciativa de pesquisa sobre a mente humana. A incorporação de um sistema teórico sobre a mente, no qual a metaforização e múltiplos modos de pensamento são incorporados, implica a adoção de uma concepção de mente 
que vá além dos limites determinados pela epistemologia moderna, embasada na cultura do homem científico. Implica, portanto, pluralizar-se a concepção de sujeito epistemológico, com base em uma concepção que o tome a partir de uma vinculação, irrecorrível, entre seu próprio potencial cognitivo e os arranjos possíveis decorrentes das inúmeras possibilidades interacionais que tomam corpo no interior dos conceitos instituídos em sua história social. Uma concepção, enfim, determinada pelo sócio-interacionismo, cujos princípios orientam a Educação do século XXI, sob a perspectiva do direito à diversidade, à identidade cultural e à autonomia.

Em contrapartida, o conceito sócio-interacionista de letramento traz de volta à centralidade os estudos sobre a teoria da gramática, esta que, propriamente, dá sentido a uma ciência lingüística. A ela, todavia, cumpre ir além de uma fenomenologia materialmente centrada na empiria descritiva, ou na alienação para com relação à pluralidade de sistemas decorrentes dos modos do pensamento, devendo instituir-se sobre o princípio da transversalidade dos sistemas em contextos metafóricos. Deste modo, seu papel é o de apresentar modelos que expliquem a primazia de $\mathrm{H}$ sobre o processo de interação com textos produzidos em inúmeros sistemas $\left\{\ldots \mathrm{T}^{\mathrm{n}}\right.$ ...\}, a partir de parâmetros geradores de feixes metafóricos de relações entre os sistemas e seus respectivos modos do pensamento.

Recebido em abril de 2005

Aprovado em maio de 2006

E-mail: senna@senna.pro.br

\section{REFERÊNCIAS BIBLIOGRÁfICAS}

Abaurre, M. et al. 2003. Estilo e gênero na aquisiz̧ão da escrita. Campinas, SP: UNICAMP.

Auraux, S. 1992. A revolução tecnológica da gramatização. Tradução portuguesa: Campinas: UNICAMP, 1994.

Bakhtin, M. 2003. A estética da produção verbal. São Paulo: Martins Fontes.

Berticelli, I. 2004. A origem normativa da prática educacional na linguagem. Ijuí, RS: UNIJUÍ.

Bloomfield, L. 1926. "Um conjunto de postulados para a ciência da linguagem". In: Dascal, M (Org.) Fundamentos metodológicos da lingüística. Vol. 1: Concepções gerais da teoria lingüística. São Paulo: Global Univ., 1978: $45-60$. 
Brandão, H. 2000. Gêneros do discurso na escola. São Paulo: Zahhar.

Сномsкy, N. 1957. Estruturas sintáticas. Tradução portuguesa. Lisboa: Eds. 70, 1980.

1965. Aspectos da teoria da sintaxe. Tradução portuguesa. Coimbra: Armenio Amado, 1978.

1966. Lingüística cartesiana. Tradução portuguesa. Petrópolis, RJ: Vozes, 1972. 1975. Reflexões sobre a linguagem. São Paulo: Cultrix, 1980.

Favero, L. 1996. As concep̧cões lingüística no Século XVIII - a gramática portuguesa. Campinas, SP: UNICAMP.

Favero, L; Andrade, M; Aquino, Z. 2000. Oralidade e escrita. São Paulo: Cortez.

Ferreiro, E et Teberosky, A. 1984. Psicogênese da língua escrita. Tradução portuguesa. Porto Alegre: Artes Médicas, 1988.

Giordan, A.; De Vecchi, G. 1990. As origens do saber. Tradução portuguesa. Porto Alegre: Artes Médicas.

Habermas, J. 1981. Theorie des kommunikativen Handelns. Frankfurt: Suhrkamp.

1990. Açôes, atos de fala, interaçoes mediadas pela linguagem e mundo da vida. In: Pensamento Pós-metafísico. Rio de Janeiro: Tempo Brasileiro: 65-104.

HawkIns, J. 1988. Explaining language universals. Oxford: Basil Blackwell.

Kant, E. 1788. A crítica da razão prática. Tradução portuguesa: Rio: CODECRI, s/d.

Kato, M. 1995. O aprendizado da leitura. São Paulo: Martins Fontes.

Lefebvre, H. 1995. Lógica formal e lógica dialética. Tradução portuguesa. São Paulo: Civ. Brasileira, s/d.

Oтте, P. 1991. O formal e o subjetivo: introdução à filosofia e à didática da matemática. Tradução portuguesa. São Paulo: UNESP, 1999.

Palmerini, M. 1976. O debate entre Noam Chomsky e Jean Piaget. Tradução portuguesa: São Paulo: Cultrix, 1983.

Popper, K. 2001. Lógica da pesquisa científica. Tradução portuguesa: São Paulo: Cultrix, s/d.

Raposo, E. 1992. Teoria da gramática. A faculdade da linguagem. Lisboa: Caminho.

SANTOMÉ, J. 1997. Globalização e pensamento interdisciplinar - o currículo integrado. Tradução portuguesa: Porto Alegre: Artes Médicas, 1998. 
SeArle, J. 1969. Os atos de fala. Tradução portuguesa: Coimbra: Almeidina, 1984.

Senna, L. 1995. Psicogênese da língua escrita, universais lingüísticos e teorias de alfabetização. ALFA, 39. São Paulo: UNESP: 221-241.

1999. Aspectos cognitivos e culturais do processo de leiturização na escola fundamental. Cadernos de Lingüística Aplicada, 33. São Paulo: UNICAMP: 23-42.

2002. Por una ciencia multicultural - la verdad como lenguaje proximal. In: ZaRATE, J. Educación y desarrollo para el futuro del mundo. Vera Cruz, MX: FESI: 410-417.

2004. Metáfora y sistemas complejos: la teoría lingüística y la descripción de estados de desarrollo proximal. Actas del. Congreso Internacional Educación, Lenguaje y Sociedad. La Pampa: Universidad Nacional de la Pampa.

Vygotsky, L. 1986. A construção social da mente. São Paulo: Martins Fontes. Wittgenstein, L. 1969. Gramática filosófica. Tradução espanhola: México/ DF, UNAM, 1992. 